\title{
Correction of the author name
}

In the published article, "Cheung KH, Alexander CG, Prompt diagnosis of ST-elevation myo cardial infarchion with papillary muscle rupture by point-of-care ultrsound in the emergency department. Clin Exp Emerg Med 2017;4(3):178-181. https://doi.org/10.15441/ceem.16.172," the second author's name has been incorrectly given. The name 'Colin Graham Alexander / Alexander CG' should be corrected as 'Colin A Graham / Graham CA.'

The authors apologize for any inconvenience it may have caused.

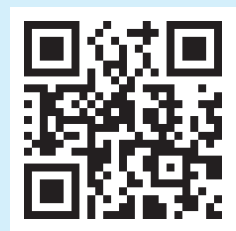

